\title{
Congenital cytomegalovirus infection: predisposing maternal factors
}

\author{
PHILIP M PREECE,* PAT TOOKEY, ANTHONY ADES, AND CATHERINE S \\ PECKHAM
}

From the Department of Paediatric Epidemiology, Institute of Child Health, London WCIN IEH

SUMMARY In a prospective study of cytomegalovirus (CMV) infection in pregnancy 69 congenitally infected infants were identified. The age, race, marital status, social class, and parity of the mothers of congenital CMV infants were compared with those of the screened population of women with non-infected infants. These factors were all individually strongly associated with the prevalence of congenital CMV. However, once age, marital status, and race were accounted for, neither social class nor parity had any additional effect. The overall congenital CMV rate was 3 per 1000 livebirths, ranging from $25 / 1000$ for single black women under 20 to $1 \cdot 6 / 1000$ in married or cohabitating white women over 25 .

Congenital cytomegalovirus (CMV) infection is common worldwide and causes significant handicap in about $10 \%$ of congenitally infected infants. ${ }^{1}$ The proportion of women with CMV antibodies varies widely between prpulations, ${ }^{2}$ as does the congenital infection rate. ${ }^{3}$ In populations with a high seropositivity rate, the majority of congenital infections result from recurrent maternal infection, ${ }^{4}$ whereas in those with a low seropositivity rate congenital infection is more often the result of maternal primary infection. ${ }^{5}$

Increased rates of congenital infection have been associated with younger maternal age, ${ }^{5-8}$ lower social class, ${ }^{9}$ single marital status, ${ }^{6-7}$ and lower parity, ${ }^{7-8}$ factors which are interrelated and associated with both race and seropositivity. To identify maternal factors associated with increased risk of congenital CMV infection the characteristics of the mothers of 69 children with congenital CMV identified in a prospective study were compared with those of the screened population.

\section{Methods}

In a study of the consequences of congenital CMV infection, infants born at three London hospitals were screened for congenital infection. ${ }^{10} \mathrm{~A}$ diagnosis of congenital CMV was made when virus was isolated from a throat swab collected in the first week of life. Infant screening took place at hospital I for 29 months

*Present address: New Cross Hospital, Wolverhampton and hospitals II and III for 55 months and 51 months respectively. A total of 69 infants with congenital CMV were identified from the three hospitals during these periods.

A prospective study of CMV infection in pregnancy was also carried out at these hospitals during part of this time. Details of maternal age, parity, race, country of birth, marital status, maternal and paternal occupations (for classification of social class) were collected at the first antenatal attendance, and a blood sample was taken to establish CMV serological status. ${ }^{10}$ Data are now available for 6584 women who booked consecutively for antenatal care over a two year period at hospitals I and II delivered live babies, and similarly for 1442 women booking consecutively over a 4.9 month period at hospital III.

Routine screening of infants for congenital CMV continued beyond the prospective study period, and a number of infants (between $5 \%$ and $18 \%$, depending on the hospital) were not screened. It was therefore necessary to estimate the denominator populations of babies who were "at risk" of being diagnosed as having congenital CMV. This was accomplished in the following way. For hospital I, 3060 women were screened over a period of 24 months, while infant screening continued for 29 months; $88.7 \%$ of babies were screened. The estimated population of mothers who were at risk of giving birth to a congenitally infected child was:

$$
3060 \times\left(\frac{29}{24} \times 0.887\right)=3280
$$


The estimated population is thus the actual population screened multiplied by a correction factor shown in brackets. For hospitals I, II, and III respectively, the correction factors were $1 \cdot 07,2 \cdot 17$, and 8.49 .

The validity of this procedure, as regards the subsequent analysis, assumes that maternal characteristics such as race, social class, marital status, and parity remained constant over the period of infant screening. We have no reason to believe that there were any demographic changes during the period of infant screening. A further assumption is that mothers of screened babies have the same characteristics as mothers of unscreened babies. As the proportion of unscreened is relatively low, the analysis and interpretation would be insensitive even to large differences.

The number of congenital CMV cases divided by the number of women interviewed was modelled by grouped logistic regression using the GLIM statistical system $^{11}$ to estimate prevalence rates, and to test for differences between subgroups. To allow for the different durations of CMV screening and interviewing in each hospital, rather than multiplying the denominators by the correction factor, a fixed term (offset) consisting of the logarithm of the correction factor for each hospital was included in each model.

\section{Results}

The estimated prevalence of congenital CMV by maternal age, race, marital status, parity, and social class is shown in table 1. Each maternal factor was strongly associated with congenital CMV, but as they are also related to each other the independent effect of each was examined.

As the rate of congenital CMV remained constant for women over the age of 25 years, women over this age were grouped together. There was a higher rate of congenital CMV in infants of black women born in Britain than in infants of black women born in the West Indies or Africa. However, as this difference was no longer present when maternal age was accounted for, black women were included as a single group. Further examination of the data by cross tabulation showed that within age and marital status groups neither parity nor social class was associated with an increased prevalence of congenital CMV. Social class and parity groups were therefore pooled. The "other" social class group included mainly single women who were unemployed or had no classifiable occupation or women with partners who were unemployed. The higher rate of congenital CMV infection in this group (table 1) could be accounted for by young maternal age and single marital status.

Table 2 shows the prevalence of congenital CMV by age, race, and marital status. The prevalence of
Table 1 Prevalence of congenital CMV by maternal characteristics

\begin{tabular}{lrrr}
\hline & $\begin{array}{c}\text { Estimated } \\
\text { population }\end{array}$ & $\begin{array}{l}\text { Congenital } \\
\text { CMV }\end{array}$ & $\begin{array}{l}\text { Rate } \\
\text { per } 1000\end{array}$ \\
\hline Race & & & \\
Asian & 2130 & 4 & $1 \cdot 9$ \\
Caucasian & 18882 & 47 & $2 \cdot 5$ \\
Black & 2235 & 18 & $8 \cdot 1$ \\
Marital status & & & \\
Single & 3337 & 28 & $8 \cdot 4$ \\
Married/co-habiting & 19910 & 41 & $2 \cdot 1$ \\
& & & \\
Age (yr) & 1802 & 21 & $11 \cdot 7$ \\
-19 & 5063 & 23 & $4 \cdot 5$ \\
$20-24$ & 7764 & 12 & $1 \cdot 5$ \\
30+29 & 8617 & 13 & $1 \cdot 5$ \\
& & & \\
Parity & & & \\
0 & 11588 & 43 & $3 \cdot 7$ \\
1+ & 11659 & 26 & $2 \cdot 2$ \\
Social class & & & \\
Non-manual & 13107 & 32 & $2 \cdot 4$ \\
Manual & 7513 & 18 & $2 \cdot 4$ \\
Other & 2627 & 19 & $7 \cdot 2$ \\
& & & \\
Overall rate & 23247 & 69 & $3 \cdot 0$ \\
\hline
\end{tabular}

congenital infection decreased with increasing maternal age in all subgroups. In most groups, the prevalence of congenital infection was higher among single than among married or cohabiting women and higher among infants of black than of white mothers. The rate of congenital CMV in infants of Asian mothers was similar to that of white mothers. As the number of infants with congenital CMV was small in the Asian group, they have been excluded from the subsequent analyses.

To explore the interrelationship of maternal age, race, and marital status the data were subjected to a grouped logistic regression analysis (table 3 ). This showed that most of the variation between subgroups was accounted for by maternal age. Once age had been accounted for, both marital status and race remained statistically significant $\left(\mathrm{X}_{1}^{2}=6 \cdot 26,6.33\right.$ respectively $\mathrm{p}<0.025$ ). However, once age and marital status were accounted for, race explained only a small amount of the remaining variability $\left(X_{1}^{2}=3.69,0.1>p>0.05\right)$. Similarly, once age and race were accounted for, marital status explained only a small amount of the remaining variability $\left(X_{2}^{2}=3.62,0.1>p>0.05\right)$. By contrast, the effect of age after the effect of marital status and race had been accounted for was unequivocal $\left(X_{2}^{2}=20.5 p<0.0001\right)$. 
Table 2 Congenital $C M V$ by age, race, and marital status

(Each cell gives the number of congenital CMV/estimated population and rate per 1000)

\begin{tabular}{|c|c|c|c|c|c|c|}
\hline \multirow[b]{2}{*}{ Age } & \multicolumn{2}{|l|}{ Asian } & \multicolumn{2}{|c|}{ Caucasian } & \multicolumn{2}{|l|}{ Black } \\
\hline & Single & $\begin{array}{l}\text { Married or } \\
\text { cohabiting }\end{array}$ & Single & $\begin{array}{l}\text { Married or } \\
\text { cohabiting }\end{array}$ & Single & $\begin{array}{l}\text { Married or } \\
\text { cohabiting }\end{array}$ \\
\hline-19 & * & $\begin{array}{l}1 / 175 \\
5 \cdot 7\end{array}$ & $\begin{array}{l}6 / 614 \\
9 \cdot 8\end{array}$ & $\begin{array}{l}3 / 571 \\
5 \cdot 3\end{array}$ & $\begin{array}{l}9 / 361 \\
24.9\end{array}$ & $\begin{array}{l}1 / 79 \\
12 \cdot 7\end{array}$ \\
\hline $20-24$ & $\begin{array}{l}0 / 12 \\
0\end{array}$ & $\begin{array}{l}1 / 731 \\
1.4\end{array}$ & $\begin{array}{l}6 / 709 \\
8 \cdot 5\end{array}$ & $\begin{array}{l}10 / 2955 \\
3.4\end{array}$ & $\begin{array}{l}4 / 347 \\
11.5\end{array}$ & $\begin{array}{c}2 / 309 \\
6.5\end{array}$ \\
\hline $25+$ & $\begin{array}{l}0 / 18 \\
0\end{array}$ & $\begin{array}{l}1 / 1191 \\
0.8\end{array}$ & $\begin{array}{l}1 / 1012 \\
1 \cdot 0\end{array}$ & $\begin{array}{l}21 / 13020 \\
1 \cdot 6\end{array}$ & $\begin{array}{c}1 / 262 \\
3.8\end{array}$ & $\begin{array}{c}1 / 876 \\
1 \cdot 1\end{array}$ \\
\hline
\end{tabular}

* There were no screened mothers in this category but one case of congenital CMV.

Table 3 Grouped logistic regression: relative risks

(Estimated from a model with age, marital status, and race)

\begin{tabular}{|c|c|c|c|c|}
\hline & $\chi^{2}$ & $d f$ & $\begin{array}{l}\text { Relative } \\
\text { risk }\end{array}$ & $\begin{array}{l}90 \% \text { Confidence } \\
\text { interval }\end{array}$ \\
\hline $\begin{array}{l}\text { Age } \\
\qquad-19 \text { years } \\
20-24 \\
25+\text { (reference) }\end{array}$ & $20 \cdot 5$ & 2 & $\begin{array}{l}4 \cdot 81 \\
2 \cdot 73 \\
1\end{array}$ & $\begin{array}{l}2 \cdot 66-8.70 \\
1.65-4.53\end{array}$ \\
\hline $\begin{array}{l}\text { Marital } \\
\text { status } \\
\text { Married (reference) } \\
\text { Single }\end{array}$ & 3.62 & 1 & $\begin{array}{l}1 \\
1 \cdot 81\end{array}$ & $1.09-3.00$ \\
\hline $\begin{array}{l}\text { Race } \\
\text { White (reference) } \\
\text { Black }\end{array}$ & 3.69 & 1 & 1.84 & $1 \cdot 11-3.03$ \\
\hline $\begin{array}{l}\text { Estimated reference } \\
\text { Rate of CMV }\end{array}$ & & & $\begin{array}{l}1.40 \text { per } \\
1000\end{array}$ & $0.99-1.99$ \\
\hline
\end{tabular}

There were no significant interactions between these three factors in their effect on the risk of congenital CMV ( $p>0.25$ ), so for example the effect of age was constant for all races and both marital status groups. Maternal age was the most important predictor of congenital CMV infection. After age, both marital status and race were important predictors, but it is difficult to determine their relative contributions because they are so highly correlated.

Table 3 summarises the relative risk attributable to each factor derived from the model using age, marital status, and race. The risk of a woman under 20 years giving birth to a child with congenital CMV was 4.8 times the risk in women over 25 years. The risks multiply so that a young single black woman has an approximately $16(4.81 \times 1.81 \times 1.84)$ times greater risk of giving birth to a baby with congenital CMV than an older married white women.

\section{Discussion}

Various maternal factors including young age, single marital status, lower social class, and low parity have been associated with an increased prevalence of congenital CMV, but in previous studies ${ }^{5-9}$ correlations between these factors were not allowed for. In the present study, maternal age was unequivocally associated with an increased risk of congenital infection, and race and marital status showed an additional effect. In a study of primary maternal infection in pregnancy, not congenital infection, Stagno et al also noted the importance of 
maternal age. ${ }^{12}$ Although we have demonstrated that both race and marital status are also important, the independent effect of each factor could not be assessed as they were closely correlated. Eighty-eight percent of white women and $57 \%$ of black women were married. Griffiths et $a l^{13}$ concluded that for primary maternal infections in pregnancy race was more important than marital status, but, as in our study, they were strongly correlated.

Once age, race, and marital status had been taken into account there was no difference in the estimated prevalence of congenital CMV between infants born to mothers from manual and non-manual social class. This contrasts with the conclusions of Hanshaw et al, ${ }^{9}$ who reported higher rates among women of lower social class than among women of higher social class using a classification based on educational achievement as well as occupation. ${ }^{14}$ In our study, women in the "other" social class category (mainly single women with no classifiable occupation) had an increased prevalence of congenital CMV, but this was accounted for by their predominantly young age and single marital status.

In the present study, there was no increased risk of congenital infection with increasing parity. The apparent increased risk in nulliparous women was explained by their young maternal age. This conflicts with the suggestion that women who already have children are at increased risk of acquiring CMV infection in subsequent pregnancies, particularly if their children attend a nursery. ${ }^{15}$

In populations where a high proportion of women have CMV antibodies, reactivation of maternal infection accounts for a greater proportion of congenital CMV infection than does primary maternal infection. ${ }^{4}$ In our study, $82 \%$ of black women in the screened population were CMV seropositive and $45 \%$ of black congenitally infected infants were born following recurrent maternal infection. In contrast, $55 \%$ of white women in the population were seropositive and $10 \%$ of white infants with congenital CMV were born following recurrent maternal infection.

Populations with high seropositive rates have been reported to have high rates of congenital CMV. ${ }^{3}$ While this was the case in our black population, it was not so for the Asians, among whom the rate of congenital CMV was only $1 \cdot 5 / 1000$ despite a seropositivity rate of $\mathbf{9 0 \%}$. In a study in Japan, where the seropositivity rate was $94 \%$, the rate of congenital infection was also low: 5 per $1000 .^{16}$ Factors other than seropositivity must therefore influence rates of congenital infection, and more detailed studies are required to identify factors associated with reactivation of $\mathrm{CMV}$ and transmission of infection to the fetus.
We have identified maternal factors associated with an increased risk of congenital CMV. However, these same factors are not necessarily related to subsequent handicap which occurs in $10 \%$ of all congenitally infected children. ${ }^{1}$ Even in our study, currently with 10 children with congenital handicap out of 104 congenitally infected children, it is not possible to determine whether risk factors for congenital infection are different from those for congenital CMV damage. Although data from the USA suggest that congenital infection following maternal reactivation is less damaging than that following maternal primary infection, there have been an increasing number of reports of handicap in children born following recurrent maternal infection.,17,18 In our study, neurological damage occurred in both black and white infants born to mothers from all social classes and followed both primary and recurrent infection. We cannot therefore agree with the conclusions of Griffiths $e t$ al that "by virtue of recurrent maternal infection, congenital CMV is a common infection of the poor but is a common disease of the middle class". 13

We thank Robert Bond and the Department of Medical Computing, Charing Cross Hospital, and Paul Fine and Jacqueline Clarkson from the Ross Institute, the London School of Hygiene and Tropical Medicine.

This study was supported by a grant from Action Research for the Crippled Child and the Medical Research Council.

Correspondence to Professor CS Peckham, Department of Paediatric Epidemiology, Institute of Child Health, 30 Guildford Street, London WC1N $1 \mathrm{EH}$.

\section{References}

${ }^{1}$ Preece PM, Pearl KN, Peckham CS. Congenital cytomegalovirus infection. Arch Dis Child 1984: 59: $1120-6$.

2 Peckham CS, Marshall, WC. Infections in pregnancy. In Obstetrical Epidemiology. London: Academic Press, 1983.

${ }^{3}$ Stagno S, Dworsky ME, Torres J, et al. Prevalence and importance of congenital cytomegalovirus in three different populations. Pediatr 1982: 101: 897-900.

${ }^{4}$ Stagno S, Reynolds DW, Huang ES, et al. Congenital cytomegalovirus occurrence in an immune population. $N$ Engl J Med 1977: 296: 1254-8.

${ }^{5}$ Stagno S, Pass RF, Dworsky ME, et al. Congenital cytomegalovirus infection: relative importance of primary and recurrent maternal infection. $N$ Engl J Med 1982: 306: 945-9.

${ }^{6}$ McDonald H, Tobin JDH. Congenital cytomegalovirus infection: a collaborative study, epidemiological, clinical and laboratory findings. Dev Med Child Neurol 1978: 20: 471-82. 
${ }^{7}$ Larke RP, Wheatley E, Saigal S, et al. Congenital cytomegalovirus infection in an urban Canadian community. J Infect Dis 1980: 142: 647-53.

${ }^{8}$ Starr J, Bart RD, Gold E, et al. Inapparent congenital cytomegalovirus infection. $N$ Engl J Med 1970: 282: 1075-8.

${ }^{9}$ Hanshaw JB, Scheiner AP, Moxley AW, et al. School failure and deafness after silent congenital cytomegalovirus infection. $N$ Engl J Med 1976: 295: 468-70.

${ }^{10}$ Pekham CS, Chin KS, Coleman JC, et al. Congenital infection in pregnancy: preliminary findings from a prospective study. Lancet 1983: 1: 1352-5.

11 Baker R, Nelder J. The GLIM system release 3. Oxford: Numerical Algorithms Group 1978.

12 Stagno S, Cloud G, Pass P.F, et al. Factors associated with primary cytomegalovirus infection during pregnancy. $J$ Med Virol 1984: 13: 347-53.
${ }^{13}$ Griffiths PD, Baboonian C, Ashby D. The demographic characteristics of pregnant women infected with cytomegalovirus. Int J Epidemiol 1985; 14: 447-52.

${ }^{14}$ Hollingshead AB. Two factor index of social position. Newhaven: Connecticut. 1957.

15 Pass RF, Hutt SC, Reynolds DW, et al. Increased frequency of cytomegalovirus infection in children in group day care. Pediatr 1984: 74: 121-6.

${ }^{16}$ Kamada $M$, et al. A prospective study of congenital cytomegalovirus infection in Japan. Scand J Infect Dis 1983; 15: 227-32.

${ }^{17}$ Ahlfors K, et al. Secondary maternal cytomegalovirus infection causing symptomatic congenital infection. $N$ Engl J Med 1981: 305: 284.

${ }^{18}$ Rutter D, Griffiths PD, Trompeter RS. Cytomegalic inclusion disease after recurrent maternal infection. Lancet 1985; ii: 1182. 